Geopolítica(s) Revista de estudios sobre espacio y poder ISSN: 2172-3958

https://dx.doi.org/10.5209/geop.69373

\title{
Geopolítica popular del coronavirus: el poder de las viñetas editoriales de la prensa diaria
}

\author{
Heriberto Cairo $^{1}$
}

Recibido: 9 de mayo de 2020 / Aceptado: 10 de mayo de 2020

Resumen. Las viñetas editoriales de los periódicos son un campo de disputa del discurso sobre la pandemia y las representaciones geopolíticas asociadas a la misma. A través de dos casos se pretenden analizar estos discursos y representaciones. El primero se ocupa de mostrar las miradas geopolíticas cruzadas a partir de viñetas aparecidas en periódicos europeos que fueron consideradas ofensivas por el gobierno de la República Popular China y las viñetas de "respuesta" en la prensa china. El segundo se va a ocupar de la representación de la pandemia del COVID-19 en las viñetas de un dibujante muy conocido que publica diariamente en la prensa española con una mirada geopolítica crítica.

Palabras clave: pandemia de COVID-19; viñetas editoriales; geopolítica popular; mirada geopolítica;

China.

\section{[en] Popular Geopolitics of the Coronavirus: The Power of Cartoons in the Daily Press}

\begin{abstract}
The editorial cartoons of newspapers are a field of dispute for the discourse on pandemic and the associated geopolitical representations. To analyze these discourses and representations, attention is paid to two cases. The first deals with showing the cross-geopolitical views from cartoons in European newspapers that were considered offensive by the government of the People's Republic of China and "response" cartoons in the Chinese press. The second deals with the representation of the COVID-19 pandemic in the drawings of a well-known cartoonist who publishes daily in the Spanish press with a critical geopolitical gaze.
\end{abstract}

Keywords: COVID-19 pandemic; cartoons; popular geopolitics; geopolitical gaze; China.

\section{[pt] Geopolítica popular do coronavírus: o poder das charges editoriais na imprensa diária}

Resumo. As charges editoriais dos jornais são um campo de disputa do discurso sobre a pandemia e as representações geopolíticas a elas associadas. Dois casos pretendem analisar esses discursos e representações. O primeiro buscar mostrar os contrastes entre visões geopolíticas das charges publi-

1 Catedrático de Geografía Política, Facultad de Ciencias Políticas y Sociología, Universidad Complutense de Madrid.

E-mail: hcairoca@cps.ucm.es 
cadas em jornais europeus considerados ofensivos pelo governo da República Popular da China e as vinhetas de "resposta" na imprensa chinesa. O segundo caso, por sua vez, tratará da representação da pandemia da COVID-19 nas charges de um conhecido cartunista que publica diariamente na imprensa espanhola com um olhar geopolítico crítico.

Palavras-chave: pandemia da COVID-19; charges editoriais; geopolítica popular; olhar geopolítico; China.

Sumario. Introducción. 1. Las viñetas "sinófobas" y su respuesta pekinesa. 2. La mirada geopolítica crítica de El Roto. Reflexiones finales. Referencias.

Cómo citar: Cairo, H. (2020). Geopolítica popular del coronavirus: el poder de las viñetas editoriales de la prensa diaria. Geopolítica(s). Revista de estudios sobre espacio y poder, 11(Especial), 303-317.

\section{Introducción}

Hoy en día ya no hace falta justificar que las viñetas editoriales de los periódicos (cartoon newspapers) sean un objeto de análisis geopolítico. La geopolítica popular no es sólo un campo de investigación consolidado dentro del más amplio de la geopolítica crítica, sino que está en expansión y puede que de "interdisciplinarización", si seguimos los planteamientos de Saunders y Strukov (2018).

Desde que Dodds (1996) publicó su iniciático artículo sobre las viñetas de Steve Bell sobre la guerra de las Falkland/Malvinas en 1982 se abrió un interesante camino para el análisis de esta faceta de la cultura popular desde un punto de vista geopolítico. Falah, Flint y Mamadouh (2006) incluyen en un trabajo sobre las narrativas geopolíticas de la prensa en el mundo árabe sobre la intervención bélica de Estados Unidos en Irak un apartado analizando las que se contienen en las viñetas editoriales de esos periódicos. Dittmer (2007) estudia la relación con la construcción de la nación de comics como el de Watchmen o el del Capitán América, tema éste sobre el que volverá en extenso más adelante (Dittmer, 2013). Brunn (2010) se ocupó de la relación entre religión y medio ambiente analizando artículos y viñetas editoriales sobre dos desastres naturales ocurridos en 2010: el terremoto de Haití y la erupción volcánica de Islandia. Hammett (2010) a través del análisis de una viñeta satírica aparecida en la prensa en la que el presidente sudafricano, Jacob $\mathrm{Zu}$ ma, se prepara a violar a la "Señora Justicia" reflexiona sobre el Estado poscolonial, la raza, el género y, en última instancia, la independencia de los tres poderes del Estado. Las viñetas sobre el cambio climático que analiza Manzo (2012) son una muestra de comentarios geopolíticos visuales sobre las relaciones entre poder y conocimiento. Shim (2017), desde una perspectiva de relaciones internacionales, intenta mostrar la capacidad de los comics para entender mejor la visualidad en la política internacional. Thorogood (2020) en un interesante artículo intenta poner en discusión la tradición de la geopolítica popular con la geografía cultural, subrayando la materialidad cultural de las viñetas.

Manzo (2012), en el artículo ya citado, establece algunas precisiones que me parece interesante tener en cuenta. En primer lugar considera que las viñetas políticas son "una forma de discurso y comunicación visual (...) [que] surgen en determinados contextos (...) [que] inevitablemente dan forma no sólo al tema de las viñetas sino a la capacidad de los espectadores (...) para entender su contenido e interpretar sus mensajes" (p.483). Además, considera con acierto que para "ser además 
considerados geopolíticos, las viñetas políticas deben de tener una dimensión espacial o escalar" (ibidem.).

A partir de estas definiciones, vamos a analizar en esta breve intervención dos casos. El primero trata de mostrar las miradas geopolíticas cruzadas a partir de viñetas aparecidas en periódicos europeos sobre el origen del virus SARS-CoV-2, causante de la pandemia de COVID-19, que fueron consideradas ofensivas por el gobierno de la República Popular China y las viñetas de "respuesta" en la prensa china. El segundo se va a ocupar de la representación de la pandemia en las viñetas que publica diariamente Andrés Rábago, "El Roto", en el periódico El País, mostrando su mirada crítica hacia los aspectos más generales de la pandemia, pero también con un fino ojo geopolítico.

\section{Las viñetas "sinófobas" y su respuesta pekinesa}

Uno de los elementos característicos de la respuesta de las nuevas derechas populistas a la pandemia del COVID-19 ha sido la acusación de que el origen del virus fue China (en particular, un laboratorio gubernamental en Wuhan), que su gobierno no informó adecuadamente a la "comunidad internacional" poniendo en peligro a la humanidad, pero que, a pesar de todo, la "raza", los "valores" nacionales vencerían la enfermedad ${ }^{2}$. Para extender esta narrativa es preciso insistir en identificar el virus con China, y una de las formas más obvias está en su denominación. En un reportaje periodístico se alude a una rueda de prensa del presidente estadounidense, Donald Trump, a mediados de marzo en la que sus notas previas incluían una referencia al coronavirus, pero el artículo señala que "una fotografía en primer plano reveló que el Sr. Trump había usado uno de los rotuladores indelebles que usa para firmar para tachar la palabra «corona», cambiando la frase a «virus chino»" (Crowley, Wong y Jakes, 2020).

La publicación el 27 de enero de 2020 de una viñeta del dibujante Niels Bo Bojesen donde las estrellas de la bandera de la República Popular China habían sido cambiadas por imágenes del coronavirus (Figura 1) en el periódico danés conservador Jyllands-Posten es una muestra clara de esta "sinofobia" en la cultura popular. No era la primera viñeta con un contenido parecido, pocos días antes, el 23 de enero de 2020, había aparecido en un periódico belga, De Standaard, otra viñeta dibujada por Lectrr, donde las estrellas estaban sustituidas por símbolos de riesgo biológico (Figura 2). Las embajadas chinas en Dinamarca y Bélgica protestaron furiosamente por la publicación de las viñetas y pidieron su retirada, pero los editores de los respectivos periódicos rechazaron hacer tal cosa en nombre de la libertad de expresión.

\footnotetext{
2 Quizás una de las expresiones más castizas de esa presunción se la debamos al diputado de la formación española de extrema derecha Vox, Javier Ortega Smith, infectado por el virus, que proclamaba en su Twitter mientras seguía la cuarentena: "Queridos compatriotas, tras vuestras preguntas, debo compartir mi día a día desde casa. Intento mantenerme en buena forma física y mental, recargando fuerzas, mis 'anticuerpos españoles' luchan contra los malditos virus chinos, hasta derrotarlos $\square$ \#FuerzaEspaña pic.twitter.com/rZRlsY2Mf5 — Javier Ortega Smith (@Ortega_Smith) March 13, 2020” (E1 Plural, 2020).
} 
Figura 1. Viñeta de Niels Bo Bojesen publicada en el periódico danés Jyllands-Posten

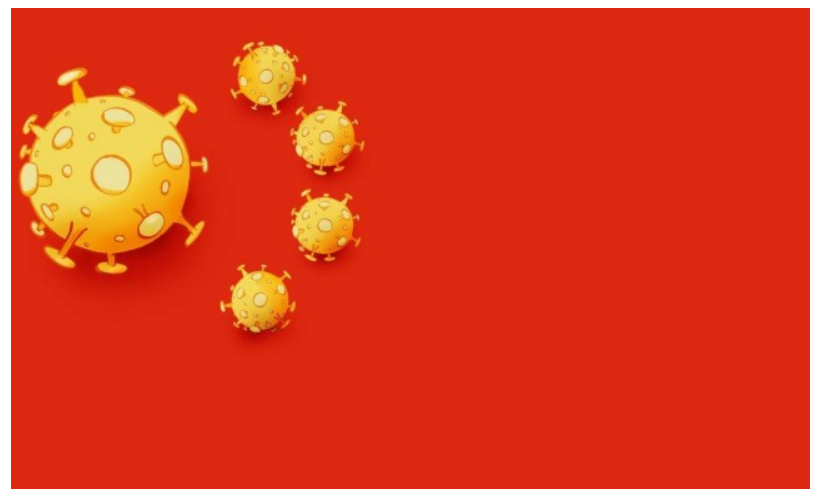

Fuente: Jyllands-Posten, 27 de enero de 2020.

Recuperado de https://jyllands-posten.dk/debat/ECE11905179/jyllandsposten-presents-view-on-cartoonin-english-and-mandarin/

Figura 2. Viñeta de Lectrr publicada en el periódico belga De Standaard

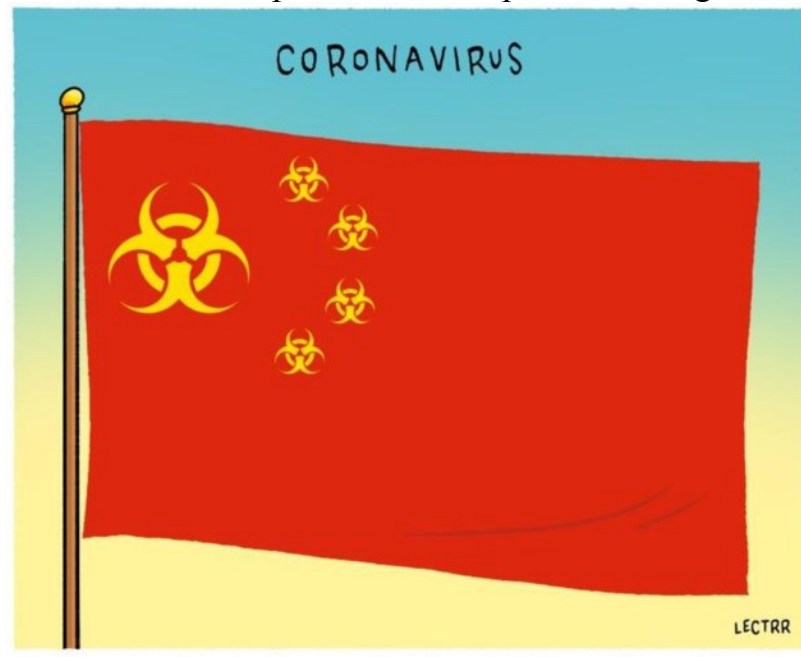

Fuente: De Standaard, 23 de enero de 2020.

Recuperado de https://www.standaard.be/cnt/dmf20200204_04834439

La diplomacia de la República Popular China insiste siempre en su argumentación de que la libertad de expresión tiene límites. Por ejemplo, el embajador chino en los Países Bajos, Xu Hong, dijo en una entrevista con De Volkskrant pocos días después de la publicación de la viñeta en Bélgica que esperaba que el gobierno holandés castigase a los medios cuando publiquen dibujos animados "hirientes" sobre el coronavirus, señalando:

Esas caricaturas no deberían convertirse en algo común. Los gobiernos occidentales dicen que eso es libertad de expresión. Pero esa libertad no está por encima de las consideraciones morales. Aprovechar este virus para atacar a un solo país, un solo pueblo, va en contra de los derechos humanos. Un periódico que imprime esto demuestra cómo se rompen las normas y los valores en el debate públi- 
co. (...) Un gobierno que considera estas publicaciones como una cuestión de libertad de expresión se descalifica como guardián de los derechos humanos. (De Standaard, 2020).

El pasado 24 de abril se publicaba también una portada de la revista satírica francesa Charlie Hebdo (Figura 3) en la que aparecía el presidente de la República Popular China, Xi Jinping, en una cama con lo que parece ser un pangolín con los labios pintados de un rojo intenso fumando un cigarrillo en una actitud estereotipada posterior a tener sexo. La reacción diplomática china fue similar.

Figura 3. Portada de la revista francesa Charlie Hebdo

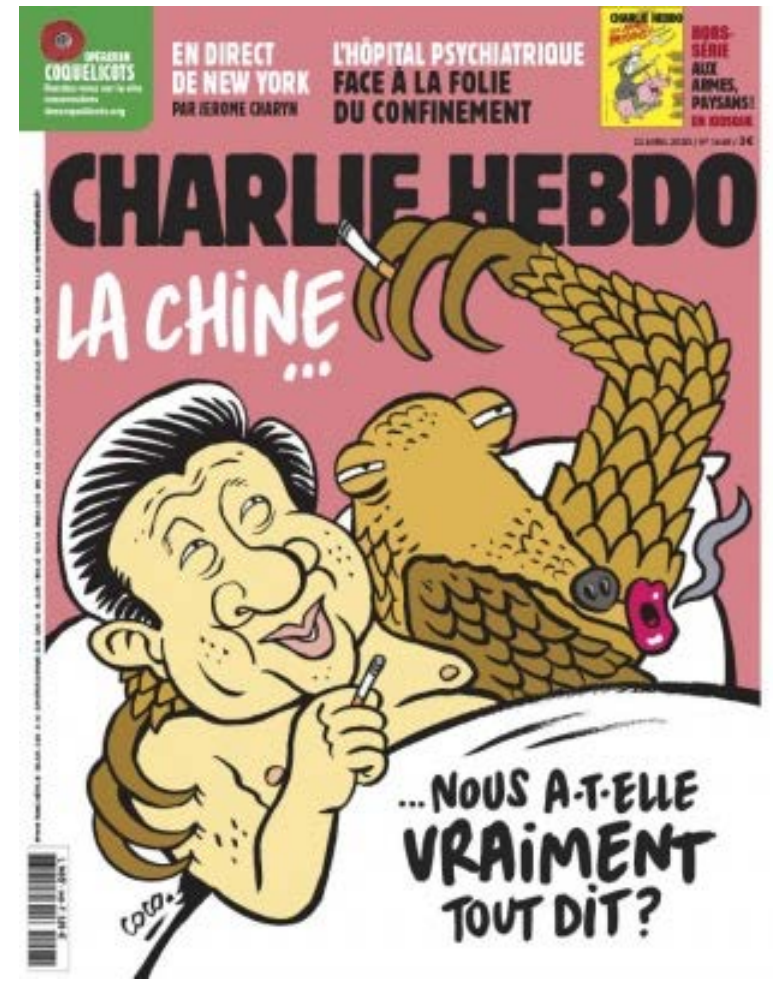

Fuente: Charlie Hebdo, 21 de abril de 2020. Recuperado de https://kiosque.charliehebdo.fr/app/last/home

Jyllands-Posten ya tenía experiencia en controversias por viñetas, lo mismo que Charlie Hebdo. Cuando se publicaron en el diario danés en 2006 unas caricaturas sobre Mahoma, que muchos musulmanes consideraron "blasfemas", las argumentaciones de base fueron similares (libertad de expresión frente al delito de odio étnico y religioso), aunque las respuestas ahora han sido diferentes. No ha habido amenazas ni atentados y sólo se han producido protestas diplomáticas. Pero, como en el caso de las caricaturas de Mahoma, estas viñetas y portada se "basaban principalmente en los viejos estereotipos" (Ridanpää, 2009, p.735), nada más que en esta ocasión en vez de ser los prevalentes acerca de los musulmanes son sobre los chinos y el régimen de la RPC, caracterizado como autoritario. Pero en ambos casos el neoorientalismo es fragrante, y las representaciones geográficas binarias 
implícitas en las viñetas insisten en la idea de un Occidente moderno y transparente frente a un Oriente tradicional y oscurantista, que es origen de peligros diversos (en esta ocasión, del coronavirus).

En el caso que nos ocupa se suma también otra geografía binaria heredera de la Guerra Fría: el Occidente democrático y liberal frente al Oriente comunista y dictatorial. El razonamiento de que la República Popular China era una dictadura y por ese motivo podía luchar contra la enfermedad sin respetar los derechos individuales de las personas ha sido constante en los medios de la nueva derecha populista $-\mathrm{y}$ en algunos otros medios conservadores-. Este del respeto a los derechos humanos individuales ha sido un argumento utilizado por estos sectores en todos los países para oponerse a las medidas de distanciamiento social promovidas por los gobiernos para intentar frenar la expansión de la enfermedad ${ }^{3}$.

La contraposición visual a este tipo de viñetas que han aparecido en los medios conservadores de los países europeos y americanos va a ser estudiada a través de las viñetas publicadas en medios chinos controlados por el Partido Comunista Chino, el órgano oficial, el diario Renmin Ribao, que se orienta al interior del país, y, especialmente, el periódico que se orienta al exterior, el China Daily. Ambos medios van a incluir en sus viñetas y anuncios las representaciones geopolíticas del régimen chino. Es decir, nos encontramos más en el terreno de la propaganda oficial que en el de la "mirada geopolítica crítica" a la que se refería Dodds (1996). Si se quiere, estas viñetas incluso se pueden considerar "intervenciones geopolíticas estadocéntricas" (Ridanpää, 2009). Pero suponen un interesante ejercicio de análisis porque, más allá de ser una expresión del punto de vista de un Estado - en particular del partido político que lo dirige-, tienen repercusión mundial, porque sus argumentos, por más esquemáticos que sean, son bien acogidos por muchas personas progresistas en las regiones de la periferia en que se produce la disputa geopolítica entre China y Estados Unidos por ampliar sus esferas de influencia y así garantizar - sobre todo el primero- el acopio de recursos naturales necesarios para sostener sus industrias y alimentar su población.

Son varios los temas de las viñetas de China Daily: la insolidaridad de Estados Unidos con el resto del mundo, el impacto sobre el capitalismo de la crisis sanitaria, que además marcaría el final de la globalización, la idea de que la tecnología protege, la necesidad de que el problema se aborde de forma global mediante la cooperación intergubernamental y, sobre todo, la injusticia e inutilidad de las acusaciones contra China en razón de la gestión de la crisis.

Las Figuras 4 y 5, del dibujante Luo Jie, recogen con precisión los argumentos de este último tema. En la primera se ve a tres "occidentales", uno claramente identificado como estadounidense por su sombrero, soplando una enorme trompeta que entona un ritmo que dice "La amenaza china" (China threat) que atruena y ensordece a un planeta maniatado a una silla. Otras viñetas argumentan que este juego de acusaciones contra China, en particular haciéndola responsable del origen del virus, es perjudicial para la lucha contra la plaga: "El juego de echar la culpa es un virus" (Blame game is a virus). Este tipo de conducta se asocia en otras viñetas con

3 En el caso español esa ha sido la gran bandera del partido de nueva derecha populista, Vox. Por ejemplo, durante el reciente debate parlamentario sobre la prórroga del estado de alarma decretado por el gobierno el presidente del partido, Santiago Abascal, denunciaba un supuesto "ataque a la libertad de expresión" del gobierno de España, que sería el "único que causa estrés a los ciudadanos, no los bulos” (ABC, 2020). 
la pervivencia de formas de pensar de otra época que impedirían pensar adecuadamente sobre la pandemia. Es, por ejemplo, el "Pensamiento de la Guerra Fría" (Cold war thinking) de la Figura 5 que impediría percibir la realidad actual: los tres monos tapan los oídos, los ojos y la boca de Estados Unidos.

Figura 4. Viñeta de Luo Jie publicada en China Daily

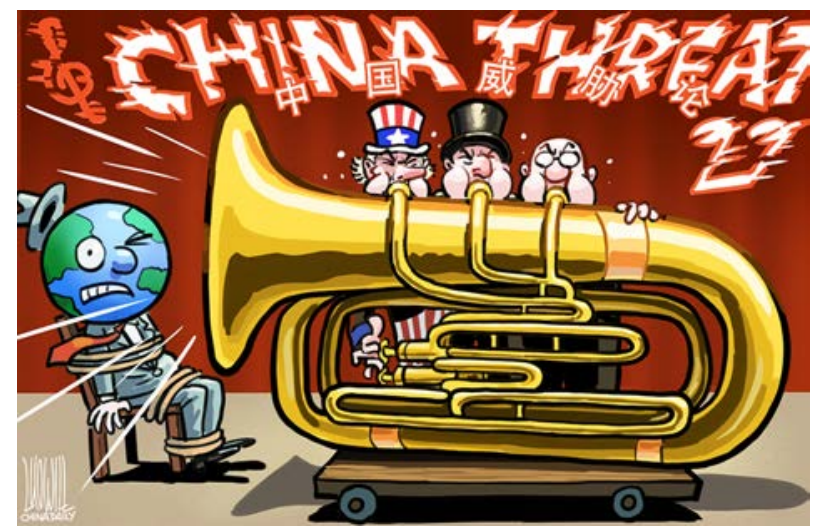

Fuente: China Daily, 21 de febrero de 2020.

Recuperado de https://www.chinadaily.com.cn/a/202002/21/WS5e4f3c94a31012821727938e.html

Figura 5. Viñeta de Luo Jie publicada en China Daily

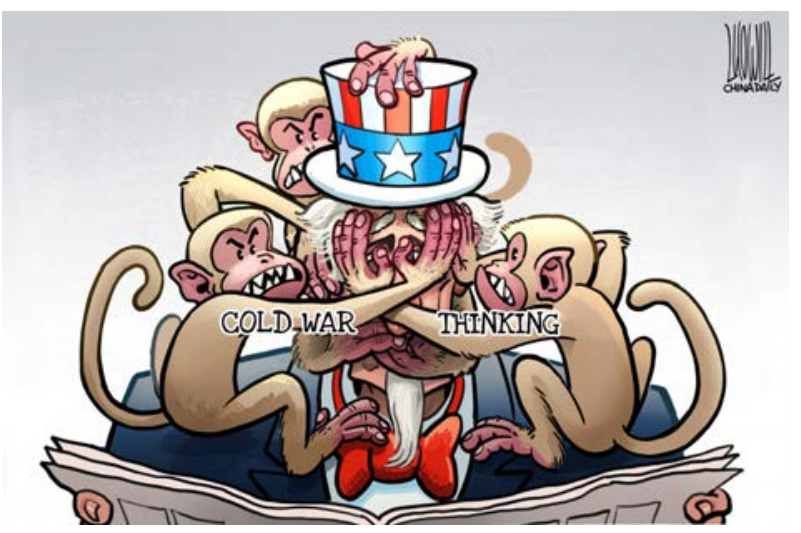

Fuente: China Daily, 21 de febrero de 2020.

Recuperado de https://www.chinadaily.com.cn/a/202003/11/WS5e6823dfa31012821727dfb2.html

La insolidaridad de Estados Unidos con el resto del mundo estaría ejemplificada perfectamente por la interrupción de la financiación a la Organización Mundial de la Salud decidida por el presidente estadounidense Trump (Klein y Hansler, 2020), a la que acusaba de mala gestión de la crisis sanitaria y complicidad con China en la ocultación del origen del virus. Así, en el dibujo de Cai Meng en la Figura 6 se ve a un enloquecido "Tío Sam" cortando con un hacha la manguera que maneja un bombero-enfermero para apagar el fuego del coronavirus. En muchas otras se enfatiza la idea de que la cooperación "global" — se suele utilizar más que "internacio- 
nal", lo cuál creo que es significativo, entendiéndose que va más allá de los actores estatales-.

Figura 6. Viñeta de Cai Meng publicada en China Daily

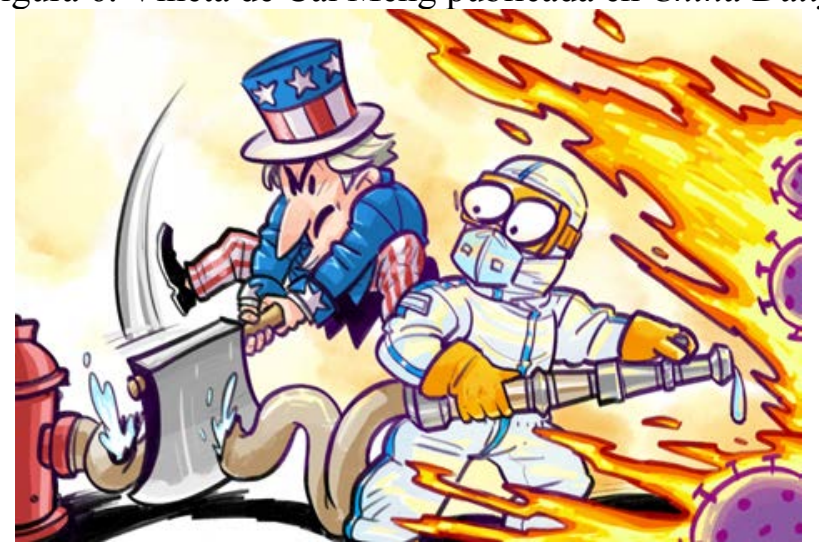

Fuente: China Daily, 16 de abril de 2020.

Recuperado de https://www.chinadaily.com.cn/a/202004/16/WS5e97a1e2a3105d50a3d16858.html

Figura 7. Viñeta de Cai Meng publicada en China Daily

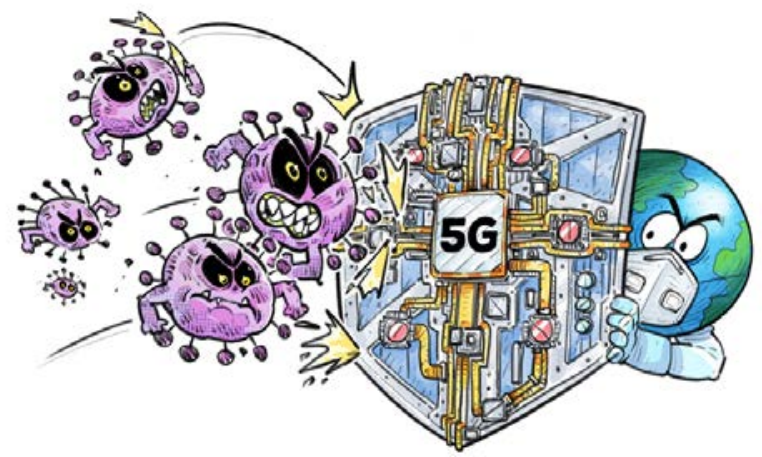

Fuente: China Daily, 19 de marzo de 2020.

Recuperado de https://www.chinadaily.com.cn/a/202003/19/WS5e72b2a4a310128217280380.html

Quisiera resaltar, por último, el mensaje de fe en la tecnología que se transmite en las viñetas, que no sólo es una reedición de la ilusión leninista de que formaba parte de la ecuación para construir un futuro feliz para la humanidad - aquello de "Comunismo = soviets + electricidad"-, sino que es sumamente significativa en medio de la pugna "geopolítica" sobre el tema de la implantación de las tecnologías de 5G digital. La Administración estadounidense ha expresado sus cautelas sobre los "problemas de seguridad" que llevaría aparejados la nueva tecnología 5G, desarrollada en buena medida por la empresa china Huawei, y los think tank conservadores han sido especialmente beligerantes a la hora de proporcionar represen- 
taciones geopolíticas que hagan inteligible este enfrentamiento ${ }^{4}$. Pues bien, la viñeta de Cai Meng recogida en la Figura 7 muestra cómo los coronavirus se estrellan contra un escudo con una trama similar a la de un microchip y el logo " $5 \mathrm{G}$ " en el centro: "La 'tequi' se ha convertido en un escudo" (Tech becomes shield).

El órgano oficial del Partido Comunista, el diario Renmin Ribao (El Diario del Pueblo) como señalábamos antes, se orienta al interior del país. No existe en este medio nada parecido a las viñetas editoriales del China Daily, aunque podríamos considerar que los dibujos que aparecen como "Publicidad" pueden desempeñar un papel similar. Pero aquí los objetivos son radicalmente diferentes: se trata de ayudar a unificar la "nación" en su esfuerzo de lucha contra la enfermedad de la COVID-19, para lo que el ejemplo seleccionado utiliza la comparación con la construcción de la Gran Muralla (Figura 8).

Figura 8. "Publicidad" política en el Renmin Ribao

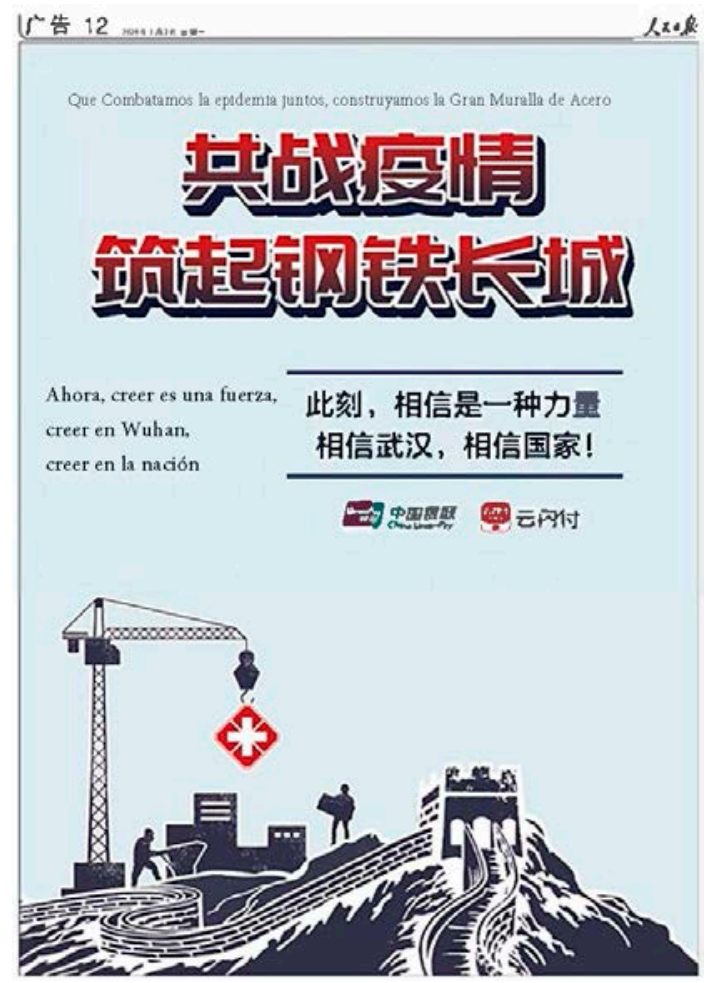

Fuente: Renmin Ribao, 3 de febrero de 2020. (Traducción de Yang Yang).

Recuperado de http://paper.people.com.cn/rmrb/html/2020-02/03/nbs.D110000renmrb_12.htm

4 Por ejemplo, John T. Watts, señala en un reciente documento de The Atlantic Council: "The West has fallen behind in the competition for leadership of the $5 \mathrm{G}$ transition, a reality that has huge economic implications and also risks the West facing the reality of a global telecommunications backbone that not only has serious security flaws, but is also shaped by political values incompatible with our own. (...) For China, being a leader in the global rollout of 5G is critical to two of its key national strategic plans: "Made in China 2025,"which aims to move its manufacturing sector up value chain and become self-sufficient in key technologies such as semi-conductors - and the Belt and Road Initiative, an international trade and infrastructure program that has become an all-encompassing foreign policy strategy." (Watts, 2020). 


\section{La mirada geopolítica crítica de El Roto}

El otro caso de estudio del que me voy a ocupar es el de las viñetas que a diario publica el pintor y dibujante Andrés Rábago, "El Roto", en el periódico El País. Se trata de un dibujante - un "poeta satírico", en palabras de Antonio Muñoz Molina (2013) - , que en palabras de un crítico, tiene una "mirada descarnada de la realidad, ajena a los tópicos", que le permite ser capaz de "desenmascarar las mentiras y las maniobras del poder" (Morales, 2018). "El Roto" entronca con una tradición ácrata, bastante extendida en España, y sus dibujos, a juicio de sus críticos, siguen las líneas de un Goya o un Grosz. Él mismo caracteriza su trabajo como "sátira social", a la que define precisamente por su labor de desenmascaramiento:

El humor puede ser un componente de la sátira pero no es su núcleo esencial. El núcleo esencial de la sátira es poner de manifiesto aquello que consideras que son falsificaciones o mentiras, las formas en las que se presentan las cosas para ser más digeribles. Arrancar esa careta es justamente lo que hace la sátira. (Entrevista con Álvarez Feáns, 2009).

Sus intervenciones gráficas sobre la pandemia del COVID-19 quizás no hayan sido sus trabajos con una perspectiva más geopolítica. Uno de sus últimos libros, Contra muros y banderas (El Roto, 2018), es sin duda una intervención mucho más crítica sobre las representaciones geopolíticas de la nación por parte de los nacionalistas excluyentes, en particular catalanes y españoles. Pero su tratamiento de la pandemia, que ha ocupado sus viñetas prácticamente desde el mes de febrero, constituye una mirada geopolítica crítica, al estilo de la de Bell que analizaba Dodds (1996).

Hay una serie de temas sobre los que ha volado la pluma de El Roto en este tiempo. Al principio fueron las viñetas sobre el miedo, la manipulación de la información y la censura, que transmitían la impotencia y la preocupación ante una amenaza sobre la que no se conocía protección. Más adelante fueron apareciendo las reflexiones sobre las causas de la situación (la destrucción de la sanidad pública por los recortes - "Cuando llegó la pandemia los neoliberales privatizadores se ocultaron" reza el título sobre un tipo con un maletín alejándose-), las consecuencias (la desigualdad social que se ampliará - "Conviene ampliar la distancia entre ricos y pobres para evitar contactos", le comenta un "rico" a otro, que le responde "Estamos en ello" mientras toman un cóctel- o la extensión de la explotación a través del teletrabajo —un reloj sin las horas marcadas-).

Los temas más específicamente geopolíticos tienen que ver con:

1) la movilidad y el cierre frente al exterior;

2) las paradojas sobre el uso de determinados espacios, y

3) la geopolítica medioambiental.

Los peligros de la movilidad y el consecuente cierre y vigilancia de territorios frente a la amenaza "exterior" ha estado estrechamente ligada al miedo, en general, pero tiene dos dimensiones específicas: la afirmación de que el sistema de movilidad asociado al modo de vida actual está ligado a la extensión de la pandemia, y el acotamiento de espacios por el miedo y la confianza en las fronteras como elemen- 
to de defensa frente a la enfermedad. La primera dimensión se refleja en las viñetas del inicio, con reflexiones sobre "el virus viajero" (viñeta del 19 de febrero) y el papel de los turistas en su difusión ("Viajar te permite conocer nuevos virus", el 31 de enero) (Figura 9). La segunda dimensión es más contundente, y apunta a que el aislamiento absoluto es una ilusión. En la viñeta del 31 de enero se muestra a un hombre armado en lo que parece ser un asteroide, dispuesto a disparar, a la vez que grita " „No se acerquen!”, que se aleja de la voluntariedad del lema oficial de

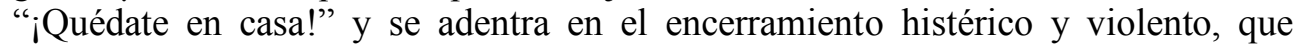
además de inútil es vano e ilusorio (Figura 10). Similar ironía sarcástica se encuentra en la viñeta del 24 de marzo, en la que se ve una mano empuñando una pistola bajo la leyenda: " ¡No temo a los virus, tengo un arma!".

Figuras 9 y 10. Viñetas de El Roto publicadas en El País

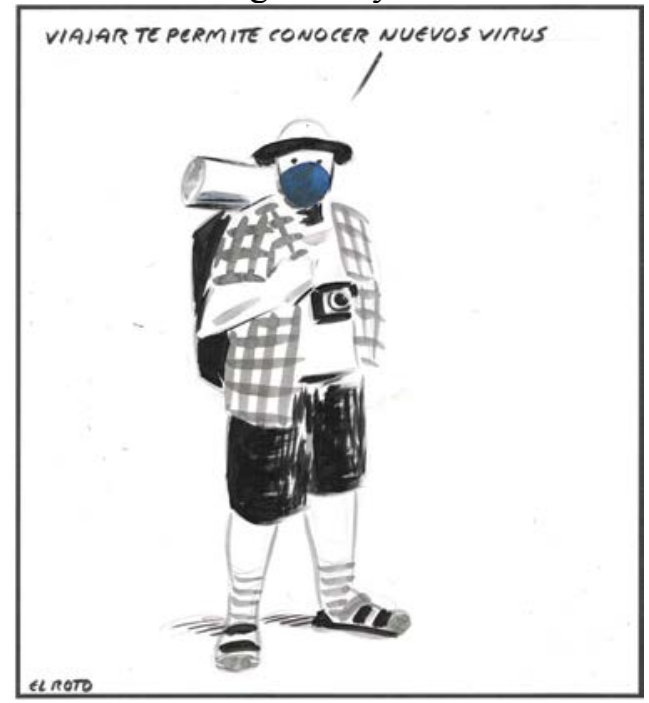

Fuente: El País, 31 de enero de 2020. Recuperado de https:/elpais.com/elpais/2020/01/30/opinion/15803927 74 901121.html

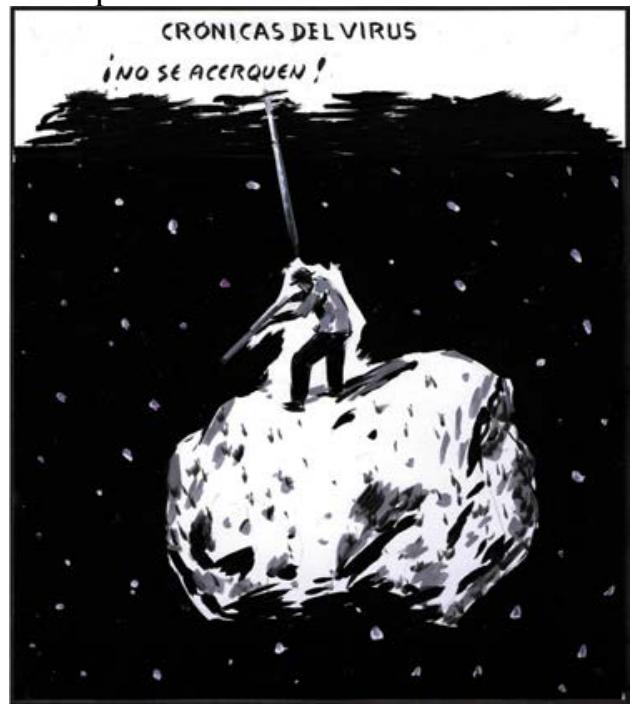

Fuente: El País, 31 de marzo de 2020. Recuperado de https:/elpais.com/elpais/2020/03/30/opinion/15855739 16 185450.html

Según el Diccionario de la Real Academia una paradoja es "un hecho o expresión aparentemente contrarios a la lógica". En los trabajos de El Roto nos encontramos con varias paradojas, comenzando por las aparentes, como la de que "Cuando estemos todos contagiados, la pandemia desaparecerá", es decir, cuando la tengamos todos ya no será una amenaza externa para ninguno de nosotros. Otras están relacionadas con la movilidad, como la del día 13 de marzo, justo un día antes de la declaración del estado de alarma por el gobierno español. El Roto se hacía eco de las prácticas irresponsables de aquellos que se desplazaban a segundas residencias o incluso lugares de vacaciones para huir de la expansión de la COVID-19 en las grandes ciudades, dibujando a un hombre en pantalones cortos escapando de las llamas: "Huyendo del fuego lo propagaban". Pero hay más paradojas espaciales en las que nos adentramos según transcurre el tiempo de encierro: descubrimos nuestras propias casas, en las que apenas permanecemos habitualmente. Un varón pregunta a su pareja en el dibujo: "iQué lugar tan raro!”, a lo que ella responde: 
"Es nuestra casa cariño" (Figura 11). Hay otra viñeta especialmente paradójica que ilustra con claridad el hecho de que es muy importante tener en cuenta los contextos locales para entender el sentido de las viñetas, porque afectan a la capacidad del "mirador" (el que mira) para interpretarlas correctamente: el 8 de abril El Roto recoge en un dibujo a la gente aplaudiendo en las ventanas para mostrar su apoyo al personal sanitario - convocatorias anónimas en todo el mundo que en España, por cierto, han intentado ser boicoteadas por la derecha populista por si implicaba algún apoyo al gobierno_-, pero lo interesante es el lema: "Efectos positivos: desaparecieron las banderas y aparecieron las personas", que hace referencia a los balcones llenos de enseñas nacionales catalanas, en buena parte de Cataluña, y españolas, en buena parte del resto del Estado, colgadas por los nacionalistas excluyentes de ambos bandos durante las recientes tensiones por los referéndums y otras actividades independentistas en Cataluña (Figura 12).

Figuras 11 y 12. Viñetas de El Roto publicadas en El País

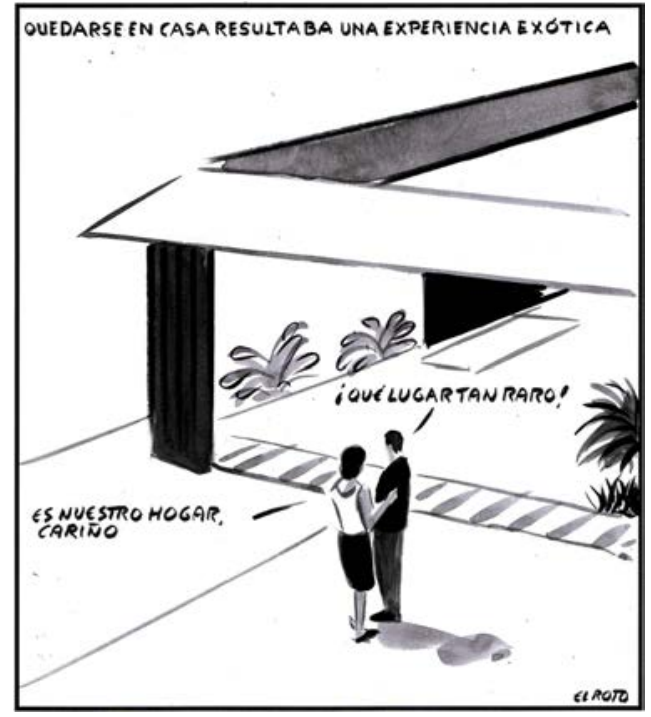

Fuente: El País, 16 de marzo de 2020. Recuperado de https:/elpais.com/elpais/2020/03/15/opinion/15842893 60 350009.html

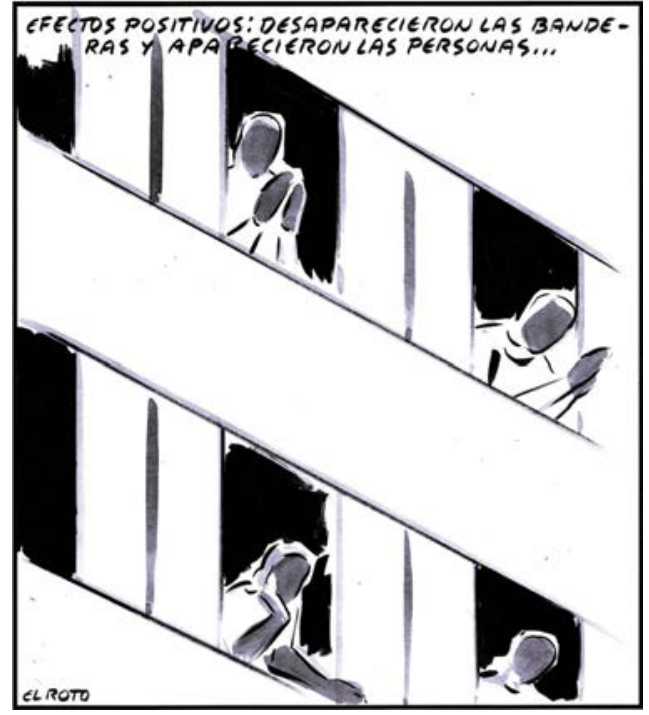

Fuente: El País, 8 de abril de 2020. Recuperado de https:/elpais.com/elpais/2020/04/07/opinion/15862604 94 155929.html

La geopolítica medioambiental es quizás el tema más importante de las viñetas de El Roto durante el tiempo de la pandemia. Aparece desde el principio y arranca una careta fundamental del "episodio", la idea de que la pandemia ha sido un accidente. La relación con una crisis medioambiental más amplia, se observa desde el 24 de febrero en que aparece un dibujo del planeta en la mano de quien parece ser un ejecutivo de empresa, cuyo título reza "La Tierra es un residuo económico", pasando por el que reproduce una rama de tomates en el que uno se ha transformado (quizás mutado) en un puño ("Rebelión en la granja"), o el que alude a la actualidad de las plagas bíblicas ("De la Biblia lo único vigente son las plagas", a lo que responde una enorme langosta "Eso creéis"), hasta el que, publicado en el día 1 de mayo, representa al planeta con el virus girando en torno a él, como si fuera una 
luna y que explícitamente dice: "La Tierra se disculpa: 'El hombre se comportaba como un cuerpo extraño, tuve que activar mis defensas" “ (Figura 13). La agresión del ser humano al planeta, derivado en buena medida de la lógica del sistema de producción imperante ha conducido a una crisis multidimensional, que ahora se manifiesta en forma de esta pandemia, pero que, evidentemente, no excluye episodios futuros mucho más mortíferos.

Figura 13. Viñeta de El Roto publicada en El País

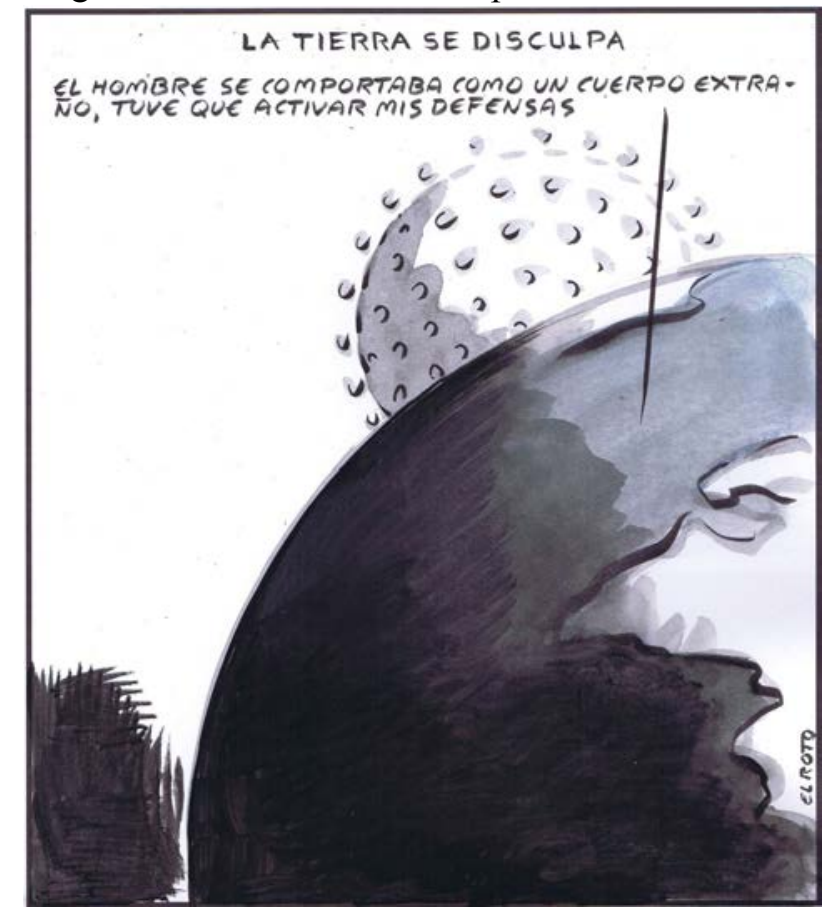

Fuente: El País, 1 de mayo de 2020. Recuperado de https://elpais.com/opinion/2020-04-30/el-roto.html

Pero además esta estrategia de denuncia permite eludir de forma radical el debate sobre el lugar de origen del virus y todas las teorías conspirativas que han abundado tanto durante la pandemia, y que tanto han contribuido al desarrollo de geoestrategias estatales de miedo y rechazo al extranjero, al inmigrante, al que no pertenece a la comunidad... Y apunta a las causas últimas de la pandemia.

\section{Reflexiones finales}

La mirada geopolítica crítica de El Roto supera a través de la sátira las geografías binarias de la imaginación geopolítica moderna (Agnew, 2005), poniendo el foco sobre la amenaza global que supone para el equilibrio ecológico del planeta el actual sistema económico de producción. Ya no es sólo la amenaza futura del cambio climático, sino que hemos tenido en tiempo presente una catástrofe sanitaria que tiene un origen en la insostenibilidad del modo de vida que pretendemos llevar la mayor parte de los habitantes del planeta. 
Pero las viñetas sirven para muchas cosas, no siempre responden a un ojo geopolítico crítico. Algunas reproducen las narrativas geopolíticas de odio que pretenden responsabilizar a un lugar, un Estado, un grupo social o una cultura de las amenazas contra "nuestra" forma de vida, y hacen inteligibles las geoestrategias securitarias de los Estados. Otras responden a representaciones geopolíticas estadocéntricas propias de actores estatales que pugnan por legitimar sus políticas internacionales en la lucha por la supremacía en el sistema de Estados.

El estudio de las viñetas editoriales hasta ahora ha solido centrarse en las miradas geopolíticas críticas, pero los dibujantes (y sus editores) a menudo no comparten esa perspectiva. El estudio de otro tipo de representaciones geopolíticas visuales es también útil. De este modo la geopolítica popular irá extendiendo su campo de estudio, a lo que espero que haya contribuido esta pequeña intervención en tiempos de COVID-19.

\section{Referencias}

ABC. (2020). Vox no apoyará la prórroga del estado de alarma porque no quiere que Sánchez "acumule más poder". $A B C, 22$ de abril. Recuperado de https://www.abc.es/espana/abci-no-apoyara-prorroga-estado-alarma-porque-no-quieresanchez-acumule-mas-poder-202004221045 noticia.html

Agnew, J. (2005). Geopolítica: una re-visión de la política mundial. Madrid: Trama Editorial.

Álvarez Feáns, A. (2009). Andrés Rábago, El Roto: "Si no nos hacemos preguntas es porque hay demasiado ruido". Pueblos. Revista de Información y Debate, 28 de abril. Recuperado de http://www.revistapueblos.org/blog/2009/04/28/andres-rabago-el-roto-sino-nos-hacemos-preguntas-es-porque-hay-demasiado-ruido/

Brunn, S. D. (2010). Cartooning and googling god and natural disasters: Iceland's volcanic eruption and Haiti's earthquake. Mitteilungen der Osterreichischen Geographischen Gesellschaft, 152, 251-275.

Crowley, M., Wong, E., y Jakes, L. (2020). Coronavirus Drives the U.S. and China Deeper Into Global Power Struggle. The New York Times, 22 de marzo. Recuperado de https://www.nytimes.com/2020/03/22/us/politics/coronavirus-us-china.html

De Standaard. (2020). 'Coronacartoons' maken China kwaad. De Standaard, 4 de febrero.

Dittmer, J. (2007). The tyranny of the serial: Popular geopolitics, the nation, and comic book discourse. Antipode, 39(2), 247-268.

Dittmer, J. (2013). Captain America and the Nationalist Superhero: Metaphors, Narratives, and Geopolitics. Philadelphia, PA: Temple University Press.

Dodds, K. (1996). The 1982 Falklands War and a critical geopolitical eye: Steve Bell and the If... cartoons. Political Geoqraphy, 15(6/7), 571-592.

El Plural. (2020). Ortega Smith muestra su día a día luchando contra "los virus chinos" con sus "anticuerpos españoles". El Plural, 14 de marzo. Recuperado de https://www.elplural.com/politica/espana/ortega-smith-muestra-luchando-virus-chinosanticuerpos-espanoles_235337102

El Roto. (2018). Contra muros y banderas. Barcelona: Reservoir Books. 
Falah, G. W., Flint, C, y Mamadouh, V. (2006). Just war and extraterritoriality: The popular geopolitics of the United States' war on Iraq as reflected in newspapers of the Arab world. Annals of the Association of American Geographers, 96(1), 142-164.

Hammett, D. (2010). Zapiro and Zuma: A symptom of an emerging constitutional crisis in South Africa? Political Geography, 29(2), 88-96.

Klein, B., y Hansler, J. (2020). Trump halts World Health Organization funding over handling of coronavirus outbreak. CNN, 15 de abril. Recuperado de https://edition.cnn.com/2020/04/14/politics/donald-trump-world-health-organizationfunding-coronavirus/index.html

Manzo, K. (2012). Earthworks: The geopolitical visions of climate change cartoons. Political Geography, 31, 481-494.

Morales, J. (2018). El Roto y Donald Trump, el Black Friday y el Cambio Climático. El Asombrario \& Co, 2 de diciembre. Recuperado de https://elasombrario.com/el-rotodonald-trump-black-friday-climatico/

Muñoz Molina, A. (2013). Relámpagos de El Roto. El País, 30 de noviembre. Recuperado de https://elpais.com/cultura/2013/11/26/actualidad/1385486581_109451.html

Ridanpää, J. (2009). Geopolitics of Humour: The Muhammed Cartoon Crisis and the Kaltio Comic Strip Episode in Finland. Geopolitics, 14(4), 729-749. DOI: $10.1080 / 14650040903141372$

Saunders, R. A., y Strukov, V. (2018). Introduction. Theorising the realm of popular geopolitics. En R. A. Saunders y V. Strukov (Eds.), Popular Geopolitics: Plotting an Evolving Interdiscipline (pp.1-20). Londres y Nueva York: Routledge.

Shim, D. (2017). Sketching Geopolitics: Comics and the Case of the Cheonan Sinking. International Political Sociology, 11(4), 398-417.

Thorogood, J. (2020). Cartoon controversies and geopolitics: Archer, animators and audiences. Social \& Cultural Geography, 21(3), 357-379.

Watts, J. T. (2020). The battle for 5G leadership is global and the US is behind: The White House's new strategy aims to correct that. Atlantic Council, 1 de abril. Recuperado de https://www.atlanticcouncil.org/blogs/new-atlanticist/the-battle-for-5g-leadership-isglobal-and-the-us-is-behind-the-white-houses-new-strategy-aims-to-correct-that/ 